\title{
Meio Ambiente e Cultura nas Capitanias do Nordeste Colonial: Nacionalismo e Reformismo Ilustrado na Obra do Naturalista Viajante Manuel Arruda da Câmara (1793-1814) \\ José Otávio Aguiar \\ Catarina de Oliveira Buriti॰
}

Resumo: Este estudo propõe suscitar uma discussão em torno das imagens e visões dos viajantes naturalistas que estiveram no Nordeste do Brasil no final do século XVIII e início do XIX a respeito do meio ambiente natural desse espaço. $O$ objetivo consiste em investigar as inter-relações entre natureza e cultura na obra do naturalista viajante Manuel Arruda da Câmara, referentes aos sertões das Capitanias do Nordeste durante a transição Colônia-Império. Observa-se que apesar desse cientista trabalhar nos Sertões das Capitanias do Nordeste colonial com vistas em satisfazer aos interesses econômicos e políticos do Reino de Portugal, ele exalta a natureza das colônias tropicais e busca também favorecer parte da população do Brasil. Nesse sentido, mesmo pertencendo à "geração ilustrada" luso-brasileira, o nacionalismo desse naturalista o levou a valorizar o meio ambiente colonial.

Palavras-chave: Meio ambiente; História; Viajantes; Brasil colonial.

\footnotetext{
- Unidade Acadêmica de História e Geografia - Universidade Federal de Campina Grande - UFCG - 58429-900 - Campina Grande - Paraíba Brasil. E-mail: j.otavio.a@hotmail.com

- Mestranda em História - Universidade Federal de Campina Grande UFCG - 58429-900 - Campina Grande - Paraíba - Brasil.

E-mail: catyburiti@yahoo.com.br
} 


\section{Considerações preliminares}

O significativo acervo produzido por artistas, naturalistas e cientistas-viajantes sobre a paisagem natural do Brasil, nos últimos decênios do século XVIII e no alvorecer do século XIX, fornece-nos visões e versões diversificadas que nos permitem conhecer diferentes percepções sobre a sociedade lusobrasileira e sobre as suas interações culturais com o meio ambiente.

A presença de viajantes e naturalistas estrangeiros e seus relatos publicados sobre o Brasil datam do século XVI. Existem mais de 260 obras, em várias línguas, nas quais os autores falam dos habitantes, da vida social, dos usos e costumes, da fauna, da flora e de outros aspectos da antiga América portuguesa, principalmente durante o século XIX, depois que Dom João VI decretou a abertura dos portos brasileiros, em 1808. Com isso, houve um incremento da navegação, o estabelecimento de laços diplomáticos e o consequente aumento da presença estrangeira no país.

Sabe-se que, de algum modo, tais imagens contribuíram para a formação da identidade do Norte (atual Nordeste) e, não obstante esses registros e representações do nosso passado colonial e monárquico resultem de intencionalidades e tradições díspares, tais fragmentos contribuíram para compor histórias e forjar memórias específicas sobre o seu meio ambiente.

Observa-se que apesar de uma vasta historiografia ter-se debruçado no estudo de tais narrativas a respeito de alguns espaços biogeográficos do país, principalmente da região central da Mata Atlântica e do bioma Cerrado localizado no Planalto Central, no que se refere às Capitanias do então Norte, apenas esparsos escritos históricos têm sido elaborados com o intuito de atentar para o olhar dos naturalistas viajantes em torno da paisagem litorânea e sertaneja dessa região.

Muitos dos botânicos, naturalistas e viajantes que vieram ao Brasil, guiados por princípios e teorias da ciência praticada na Europa nos séculos XVIII e XIX, coletaram e enviaram informações encomendadas pelas Academias Reais de Ciências, 
com vistas a satisfazer as necessidades utilitárias da Corte portuguesa. Nesse sentido, era necessário conhecer e explorar os recursos naturais dessas Capitanias com vistas em favorecer a sua exploração comercial.

Dessa grande quantidade de estrangeiros, viajantes e aventureiros (ingleses, franceses, alemães, portugueses) que escreveram suas impressões e crônicas sobre o Brasil, destacam-se aqueles que se embrenharam nos Sertões do Nordeste brasileiro - espaço fitogeográfico conhecido atualmente como Nordeste - e que elaboraram seus relatos sobre a paisagem e os povos da região, dentre os quais, o inglês Henry Koster, o francês Louis François de Tollenare e o naturalista brasileiro com formação européia Manuel Arruda da Câmara. Este último constitui-se como um importante fitologista brasileiro cujos trabalhos estão ainda praticamente inéditos, ignorados e esquecidos, passíveis, portanto, de análises com maior profundidade analítica. A sua obra será tomada como objeto da presente pesquisa.

A peculiaridade dos trabalhos de Manuel Arruda da Câmara reside no fato de que estes não foram, em última instância, apenas produto do olhar de um estrangeiro, mas de um brasileiro formado em territórios europeus, que direcionou os conhecimentos por lá construídos para analisar a sua Terra, com a sua Natureza e com a sua gente. Nesse sentido, é importante observar que não obstante estarmos nos referindo a um naturalista que investigou o meio ambiente da sua própria região, a sua formação européia e o trabalho encomendado pela Coroa certamente contribuíram para que a sua observação e análise fosse, por um lado, pré-programada e atrelada aos objetivos cientificistas europeus, e, por outro, permeado por visões e concepções nacionalistas. Podemos inferir que ao mesmo tempo em que Arruda da Câmara, semelhante aos demais viajantes estrangeiros que por aqui estiveram, atendia diretamente aos interesses da Metrópole que financiou as suas pesquisas no Brasil, também criticava, paradoxalmente, em virtude das suas concepções nacionalistas, a política colonial e a 
concepção botânica anterior da Coroa que inferiorizava a natureza brasileira.

Segundo Warren Dean (1996), Manuel Arruda da Câmara audaciosamente exaltava as riquezas naturais do Brasil em comparação com a Metrópole em crise: defendia que os países tropicais eram muito mais férteis que a Europa, que estaria em uma condição "medíocre e miserável" caso não tivesse recebido, no passado, espécies botânicas dos Trópicos. Assim se misturaram o nacionalismo e a botânica para inverter o preconceito acalentado pelos peninsulares desde a invasão.

Mais interessante, para os nossos propósitos imediatos, é o relato das viagens de Arruda da Câmara pelas matas e sertões, bordejando o bioma de Semi-árido, através de indagações e observações botânicas. Também interessante é o fato de Podermos, em síntese, elencar grupos de fontes, imagens e elementos não excludentes entre si, que exerceram presença na leitura de Arruda da Câmara sobre o sertão.

A Metrópole encarregou esse naturalista de observar e descobrir nitreiras, minas de cobre e outros minérios da região que pudesse remeter vantagens econômicas para a Coroa. Manuel Arruda da Câmara, entretanto, enviou da Paraíba diversos relatórios e cartas para a Corte, afirmando não ter-se limitado apenas à análise do reino mineral, mas as suas observações alcançaram também os reinos vegetal e animal (notadamente insetos) e a maneira como a cultura da população agrícola dos sertões se relacionou e interagiu com a natureza. Em virtude de sua preferência pela vegetação, nenhum de seus estudos remetidos à Metrópole resultou em descobertas de minerais.

A experiência de viagem, metáfora constante nas narrativas de Manuel Arruda da Câmara, pode ser encarada como uma das chaves possíveis para a construção de sua imagem do sertão. Procurando suplantar as teorias de gabinete, elaboradas por homens como Bufon e o Abade Raynal, que nunca haviam visitado as Américas, Arruda da Câmara acreditava que não bastava ler sobre ou consultar os compêndios: era preciso sentir, fisicamente inclusive, as 
dificuldades que se lhe apresentavam previamente; era preciso pôr em tensão as próprias representações, as memórias, as experiências de outrem que lhe eram relatadas. É sobre esse "arquivo dos pés" ${ }^{1}$ resultante das indagações, observações e experiências realizadas por Arruda da Câmara que buscamos desvendar as historicidades presentes nessas fontes.

Nesse quadro de referências, o objetivo geral deste trabalho consiste em investigar as inter-relações entre natureza e cultura na obra do naturalista viajante Manuel Arruda da Câmara, referentes aos sertões das Capitanias do Norte durante a transição Colônia-Império. Delineamos a seguir os objetivos específicos norteadores da presente pesquisa: a) compreender o contexto social e político europeu que impulsionou a corrida pela exploração de recursos naturais favoráveis ao comércio da Coroa portuguesa, situando as viagens científicas e exploratórias realizadas como consequencias do naturalismo-utilitário; b) identificar a peculiaridade das observações e experiências de Arruda da Câmara e as inter-relações das sociedades com a natureza dos Sertões nortistas, entre o período de 1793 a 1820; c) analisar fragmentos de descrições da paisagem natural, de forma a estabelecer um cenário ambiental e humano das Capitanias do Nordeste colonial em fins do Setecentos e na primeira década do Oitocentos; d) investigar se a narrativa científica de Manuel Arruda da Câmara tinha preocupações conservacionistas a respeito da natureza luso-brasileira; e) elaborar uma história do bioma Semi-árido visitado pelos viajantes e naturalistas que percorreram os Sertões por ocasião de sua viagem ao Nordeste Brasileiro durante a transição Colônia-Império.

O trabalho foi desenvolvido com base na análise dos escritos do naturalista viajante em estudo, confrontando-se os dados catalogados e coletados com a bibliografia que aborda o contexto de produção das viagens científicas. A problemática consiste em analisar a visão que esse naturalista elaborava a respeito dos espaços luso-brasileiros que visitava, no caso, dos Sertões das Capitanias do Nordeste colonial, defendendo a premissa de que mesmo com as suas preocupações 
nacionalistas de valorizar o ambiente natural e desconstruir os estereótipos europeus de natureza exótica, as indagações de Arruda da Câmara, assim como dos demais reformistas ilustrados sócios da Academia Real de Ciências de Lisboa, recorriam em torno das potencialidades comerciais agrícolas da terra e da flora da região.

\section{O itinerário de viagem de Manuel Arruda da Câmara pelos Sertões do Nordeste}

Em 1793, Manuel Arruda da Câmara, regressando dos seus estudos na Europa com encargos científicos confiados e financiados pela Coroa portuguesa, que lhe incumbiu de realizar diversos levantamentos naturais na região Nordeste do Brasil, iniciou o seu percurso pelo Sertão nordestino. Aplicando seus conhecimentos na área de História $\mathrm{Natural}^{2}$, estudos de Agricultura e Botânica, dedicou-se à observação e à descoberta dos produtos vegetais, animais e minerais da região favoráveis ao desenvolvimento da Coroa portuguesa. O itinerário seguido pelo cientista-viajante compreende:

- Entre Março de 1794 e Setembro de 1795, fez uma expedição mineralógica entre Pernambuco e Piauí, levantando a ocorrência de diversos minerais;

- Entre Dezembro de 1797 e Julho de 1799, percorreu os sertões da Paraíba ao Ceará;

- Realizou viagens até o rio São Francisco.

Procuramos, pois, neste trabalho, delimitar vestígios do cotidiano das populações destes trechos do sertão nordestino, identificando a forma como a sociedade interagiu com o meio ambiente e se apropriou culturalmente da vegetação específica da região e com outros elementos da flora trazidos de outras partes do mundo para aclimatação nos Trópicos. O recorte espacial e cronológico delimitado baseou-se, respectivamente, no itinerário que esse naturalista seguiu pelos sertões das 
Capitanias do então Norte, que corresponde aos territórios e biomas descritos pelo cientista ora estudado na tentativa de elaborar um quadro do ambiente natural, da relação estabelecida entre Natureza e cultura agrícola da população, e às datações das obras publicadas descrevendo os resultados das observações e experiências.

Tais aspectos se inter-relacionam intimamente, já que, no processo de humanização da Natureza, construímos, enquanto sociedades, aquilo que chamamos de paisagem humanizada. Esta paisagem ${ }^{3}$ esculpida pelas mãos de diferentes atores históricos em uma zona de contato colonial será nosso objeto.

As informações biográficas mais prováveis de Manuel Arruda da Câmara asseveram que o cientista nasceu no ano de 1752, na cidade de Pombal, sertão da Paraíba e faleceu em Itamaracá, em Pernambuco, no ano de 1810. Foi um religioso, médico e intelectual brasileiro que se notabilizou como um dos grandes botânicos do final do século XVIII. A partir de 1783, após ter professado a regra dos Carmelitas calçados no Convento de Goiana, em Pernambuco, viajou para Portugal, onde se matriculou na Universidade de Coimbra, formando-se em Filosofia Natural. Em 1790, foi para a Universidade de Montpellier, na França, onde recebeu o grau de doutor em Medicina.

Retornando ao Brasil, sob a influência do ideário da Revolução Francesa, não se conformou com o quadro de injustiça social reinante e apressou-se em trabalhar visando a combater, sobretudo, em favor das famílias mais humildes, maiores vítimas do sistema patriarcal. Nesse sentido, fundou o Areópago de Itambé, Sociedade Maçônica que abrigava intelectuais da Paraíba e de Pernambuco e onde foi tramada a Revolução de 1817, cujas estimativas apontam a participação do naturalista em favor desse movimento.

Embrenhado pelos Sertões nortistas, classificou a flora da Paraíba ${ }^{4}$, redigiu escritos sobre a agricultura e a Flora de Pernambuco (Centúrias dos novos gêneros e espécies das plantas pernambucanas). No conjunto de suas expedições científicas, realizou levantamentos mineralógicos, botânicos e zoológicos 
por ele próprio sistematizados sob a forma de inúmeros trabalhos científicos.

Deixou uma importante obra, dentre as quais, tomamos como fonte para este estudo: A memória sobre a cultura do algodoeiro, 1797; Dissertação sobre as plantas do Brasil, 1817; Discurso sobre a vitalidade da instituição de jardins nas principais províncias do país, 1810; Aviso aos lavradores sobre a suposta fermentação de qualquer qualidade de grãos ou pevides para aumento da colheita, Lisboa, 1792; Memórias sobre as plantas de que se podem fazer baunilha no Brasil, (nas memórias da Academia Real das Ciências de Lisboa, v. 40, 1814); Memórias sobre o algodão de Pernambuco, Lisboa, 1810; Tratado de Agricultura; Tratado da lógica.

Manuel Arruda da Câmara poderia ser considerado um reformista ilustrado, ao lado de uma geração de brasileiros que se projetaram na história científica e política do país, dentre os quais, aquele que ficaria conhecido como o patriarca da independência, José Bonifácio de Andrada e Silva.

$O$ conjunto de idéias que se convencionou chamar iluminismo nunca constituiu uma unidade de princípios, um todo harmônico e universal. A busca do progresso das ciências e das técnicas, o anseio pela organização de uma nova sociedade baseada nos princípios de igualdade e de liberdade políticas, de uma forma de assegurar aos homens e mulheres a felicidade, entendida como conquista ao alcance de todos, uniu muitos dos autores que comumente associamos ao estandarte das luzes. Estendendo suas raízes ao humanismo do século XVI, esse movimento intelectual de valorização da razão só se afirmou efetivamente a partir do século XVII inglês, alcançando, enfim, o seu ápice no século XVIII, quando, a partir da França, alastrouse por toda a Europa, alcançando quase simultaneamente o Novo Mundo. Cabe, no entanto, observar que nunca houve uma só proposta ilustrada de mudança social e que o objetivo final para a maioria esmagadora dos filósofos era uma reforma e não uma subversão violenta e revolucionária da sociedade. Buscavase a reconstrução da civilização humana em novas bases mais 
racionais e menos "obscuras", e isso poderia ser conseguido por meio de um monarca esclarecido.

Os mesmos princípios, talvez ligados entre si pelo culto à racionalidade e aos direitos naturais do homem, que embasaram revoluções na Inglaterra seiscentista, na França e nas Treze Colônias Inglesas no Setecentos, originaram, em outros países da Europa, a política do Reformismo Ilustrado, segundo a qual o soberano, concebido agora como servidor do Estado e não como a sua própria encarnação, promoveria as reformas necessárias no plano político, educacional e econômico. No Brasil, livros de Rousseau, Voltaire, Montesquieu e Raynal figuravam nas bibliotecas dos sediciosos mineiros de 1789; tiveram também seu lugar na Inconfidência Baiana e na Revolução Pernambucana de $1817^{5}$.

Em Portugal, como de resto na Prússia, na Rússia, na Toscanna, no Reino de Nápoles e na Espanha, a absorção do iluminismo por parte de seus governantes e ministros incluiu a adoção de alguns princípios inovadores, e motivou a implementação de reformas que, acreditava-se, precederiam sua reivindicação por parte do povo. Distanciavam-se, assim, esses países dos projetos de reestruturação do pacto social, que previam um aumento do nível de participação política, rumo a uma sociedade democrática.

Homens como o Marquês de Pombal, ministro Dom José, monarca português que reinou entre os anos de 1750 e 1777, entendiam que, sendo o estado de natureza um estado de caos, carente de organização política, no qual as garantias e liberdades básicas dos homens encontravam-se ameaçadas, cabia ao estado reforçar o poder absoluto do Rei, como medida necessária para que se garantissem os direitos naturais. A reforma administrativa pombalina, responsável pela reafirmação do absolutismo lusitano, buscou uma reorganização da estrutura governamental no intuito de conseguir uma maior eficiência na máquina burocrática do império ultramarino. Expulsaram-se os jesuítas e submeteu-se a catequese e a direção dos índios brasileiros diretamente ao Estado. Incentivou-se a atividade manufatureira em solo português e o comércio com o Brasil. 
Reformou-se ainda o ensino, particularmente o universitário ao qual seria incorporado um currículo de orientação ao mesmo tempo jusnaturalista ${ }^{6}$ e pragmática. No Colégio dos Nobres e na Universidade de Coimbra, as disciplinas marcadas pela escolástica medieval e teológica perdiam espaço, pois se buscava orientar os alunos em direção a uma exploração planejada e racional do potencial das colônias. Isso porque se formavam acima de tudo os jovens que, pela sua origem social, destinavam-se à futura direção do Estado, e, neste sentido, entravam no currículo as matemáticas, as ciências naturais, as línguas vivas. Dentre os formandos de Coimbra, figuravam futuros estadistas como o naturalista Rodrigo de Souza Coutinho e o mineralogista brasileiro José Bonifácio de Andrada e Silva ${ }^{7}$.

O objetivo fundamental de promover a modernização econômica e cultural de Portugal sem, no entanto, deixar de subordiná-la ao poder do Estado, sobreviveu à morte de Dom José I e à subida de Dona Maria I ao poder, logo seguida do afastamento do Marquês de Pombal em 1777, figurando ainda como horizonte de seus ministros sucessores para além da transferência da corte portuguesa para o Brasil.

Extremamente dependente da produção colonial, Portugal recebia com certo incômodo a mensagem das Luzes, devido ao perigo de que as concepções de liberdade e igualdade invadissem seus domínios ultramarinos. A dominação colonial, questionada até então em termos teológicos e somente no tocante à escravização indígena, passou a ser discutida em solo brasileiro, principalmente a partir do último quartel do século XVIII, quando movimentos sediciosos com planejamento e orientação revolucionária levantaram-se no Brasil.

Em 1796, com a morte de Martinho de Melo e Castro, Dom Rodrigo de Souza Coutinho foi nomeado ministro das colônias e da Marinha, iniciando uma política estratégica de absorção dos conhecimentos científicos estrangeiros, vistos como meio de racionalizar a exploração colonial e garantir a lealdade dos súditos de além-mar, frente à ameaça que os exércitos e as idéias da França representavam para a metrópole lusitana. Sua política de valorização dos saberes científicos afirmava-se contra 
uma série de tendências que neles viam, dada a sua associação com os pressupostos da ilustração, um meio de penetração de pressupostos subversivos à ordem vigente. Muitos cientistas naturais foram perseguidos em Portugal sob a alegação de que eram ateus ou portadores das "perigosas idéias francesas".

O que Souza Coutinho buscava, para além das desconfianças do conservadorismo português, era atrair o apoio da elite colonial, formada em Coimbra, ao ideal de construção de um grande e poderoso império português ${ }^{9}$. Seis anos antes da transferência da Corte para o Brasil, já a recomendava como indispensável, afirmando que, devido às suas condições geopolíticas e naturais, a América portuguesa deveria representar a sede desse império ${ }^{10}$. Renunciando ao cargo em 1803, sob a pressão constante dos que o acusavam de anglofilia, continuou a preconizar a transformação do Império Ultramarino Português numa confederação de iguais. Mais tarde, voltaria ao poder no Brasil, sob o título de Conde de Linhares, continuando seu programa de reformas e incentivo às ciências. Contrariando sua formação iluminista, defendeu, ao longo de toda a sua carreira política, os interesses escravistas, vinculando-os aos investimentos nos setores agrícolas do Brasil.

É bom lembrar, nesse contexto, que, com a crise do Antigo Sistema Colonial português a partir do desmoronamento do modelo de exploração centrado hegemonicamente em uma política econômica mercantilista, o investimento nas ciências foi colocado como alternativa para o redirecionamento do sentido da colonização lusa nos Trópicos, fato que provocou a redescoberta da América portuguesa no último quartel do século XVIII. A Coroa acumulou forças com o objetivo de criar uma burocracia especializada e profissional no Reino e nos seus Domínios, sendo Dom Rodrigo de Souza Coutinho, agora nomeado Ministro de Ultramar, responsável pela reintegração e exploração natural das Colônias.

A Academia Real de Ciências de Lisboa foi o instrumento através do qual os intelectuais ilustrados buscaram a construção científico-utilitária do Mundo Natural das Colônias, com vistas em superar a crise interna do reino luso, sendo considerada 
como uma instituição aparelhada para instruir a política colonial através de suas pesquisas empíricas que poderiam recuperar econômica e politicamente a Metrópole, diante da forte pressão competitiva empreendida pelas potências européias.

Ao longo do século XVIII, a Coroa portuguesa perdeu gradualmente o controle do Mundo Colonial, o que instigou o sub-grupo de intelectuais naturalista-utilitários da Academia a defender que cabia ao Mundo de Queluz a condução de uma política colonial capaz de incorporar as experiências realizadas pelos exploradores ao longo das viagens pelo Império ultramarino e as investigações desenvolvidas nas demais instituições científicas portuguesas.

Inspirados pelo pensamento das Luzes, os sócios da Academia Real de Ciências de Lisboa acreditavam que os bens naturais do Novo Mundo não deveriam ser entendidos meramente como exóticos, mas podiam ser explorados cientificamente e recuperar o Reino da crise enfrentada. A visão pragmática desses intelectuais descrevia os recursos naturais marcando as peculiaridades da botânica, das riquezas minerais e da fauna de cada uma das Capitanias que se encontravam sob o domínio português, direcionando os interesses científicos e remetendo tais singularidades às demandas econômicas do Estado luso (MONTEAL FILHO, 1999).

Desse modo, os naturalista-utilitários buscaram, ao lado dos burocratas fiéis à Coroa, recuperar o controle do Império português sobre o Mundo Natural das Colônias para que seu poder de controle fosse restituído. O empirismo e as atitudes científicas pautadas na observação e experimentação buscavam atender a objetivos econômicos imediatos e recuperar o domínio do Estado português, eis o sentido do desbravamento históricoempírico do Mundo Natural por parte desses cientistas.

Foi com essa concepção que a "geração ilustrada" lusobrasileira buscou conhecer as potencialidades naturais do Brasil. Diante de tal constatação, contrapomo-nos à posição assumida por Pádua (2004) em relação à "redescoberta" que ele acredita ter feito de uma tradição intelectual brasileira, dos séculos XVIII e XIX, que empreendeu uma "reflexão profunda e consistente 
sobre o problema da destruição do ambiente natural", "muito antes do que convencionalmente se imagina como sendo o início desse debate." (p. 10). Não obstante o próprio autor perceber que esses pensadores não defenderam o ambiente natural pelo seu valor intrínseco, mas sobretudo pela sua importância econômica e política e, por isso, pelo grande trunfo que os recursos naturais representavam para o progresso do país, é problemática a relação comparativa que ele estabelece entre o reformismo ilustrado e o ambientalismo moderno. Em um dos trechos do livro, o autor afirma que "idéias semelhantes" à crítica ambiental contemporânea já estavam sendo discutidas no Brasil durante fins do século XVIII e as primeiras décadas do século XIX, o que o leva a situar esses intelectuais como os precursores da crítica ecológica atual.

A própria denominação dada ao sub-grupo de naturalistasutilitários, conforme vimos, levam-nos a inferir que o pensamento desses reformistas ilustrados eram experimentar cientificamente os recursos naturais da Colônia, com o intuito de beneficiar a Coroa portuguesa e retirá-la da crise. Isso significa afirmar que a preservação do ambiente natural dos Trópicos não era pensada como necessária para manter a natureza viva, mas seria necessário impedir que os bens naturais fossem destruídos e desperdiçados, porque somente ao Mundo de Queluz caberia a sua exploração, para que o Estado voltasse a ter progresso econômico e reconhecimento político.

Warren Dean ressalta que foi somente depois de quase três séculos após o início da colonização portuguesa que o Mundo Natural do território brasileiro começou a chamar a atenção das autoridades da Corte, com o intuito de explorar científica e comercialmente as riquezas naturais da Colônia, justamente em fins do século XVIII, quando o interesse científico europeu estava se voltando mais sistematicamente à exploração da natureza, para além de suas fronteiras.

Uma das preocupações da Coroa era estreitar as suas relações com os territórios coloniais, considerando que à medida que as outras potências européias estavam desenvolvendo as suas colônias tropicais, a Monarquia portuguesa perdia seu 
mercado ultramarino, a partir de então alvo comercial dessas outras potências. Nesse sentido, os perspicazes botânicos e cientistas patrocinados pelo Rei exerceram um importante papel no conhecimento dos recursos naturais das colônias tropicais, fundando sociedades científicas, museus de história natural, realizando expedições científicas, entre outras atividades voltadas para a experimentação e catalogação de espécimes capazes de promover a diversificação agrícola e a aclimatação de plantas úteis à economia da Metrópole.

No Brasil, a primeira sociedade científica de que se tem notícia foi fundada em Salvador, em 1759, e se propunha a fazer estudos a cerca da agricultura, da fauna, da flora e dos minerais. Warren Dean salienta que parece que os intentos dos seus sócios não foram levados adiante, e se o foram, não deixaram vestígios destes estudos.

Uma segunda sociedade foi criada no Rio de Janeiro, em 1772, pelo vice-rei marquês do Lavradio, a Academia Fluviense, cujo objetivo era pesquisar sobre a medicina, a cirurgia, a botânica e a farmácia. Esta academia, apesar de sua breve existência, conseguiu recuperar um jardim botânico dos jesuítas e nomear jardineiros, coletores e botânicos para administrá-la. O novo vice-rei que sucedeu o Marquês do Lavradio, Luís Vasconcelos de Souza, construiu a mando da corte um Museu de história natural e procurou ressuscitar a Academia na forma de Sociedade Literária, que, por seu turno, foi extinta em 1790, com a substituição do vice-rei. Tais tentativas de implantação de sociedades científicas no Brasil e o fato de não terem logrado resultados, levam-nos a concordar com Dean (1996), que afirmava serem os principais empecilhos para o ingresso das ciências no Brasil o que ele chamou de "descontinuidade administrativa".

Somente em 1808, foi instituído o Jardim Botânico do Rio de Janeiro tendo como uma das suas incumbências receber e aclimatar plantas tropicais de interesse econômico. Essa implantação foi uma das primeiras iniciativas do ministro Rodrigo de Souza Coutinho, quando se deu a transferência da Corte portuguesa para o Brasil, que não hesitou em instalar 
poderosos instrumentos de investigação do mundo natural. Conforme iremos observar a seguir, Manuel Arruda da Câmara foi um dos naturalistas que buscou instalar na província de Pernambuco um jardim botânico necessário à aclimatação de espécimes nacionais e das diversas partes do mundo.

\section{O meio ambiente do Nordeste colonial em Manuel Arruda da Câmara}

José Antônio Gonsalves, desbastando a biografia de Manuel Arruda da Câmara, com o intuito de desmitificar certas visões elaboradas a respeito do cientista viajante, assim situa a atuação política dele nos sertões das Capitanias do Nordeste colonial:

[...] Um homem dedicado ao estudo das ciências naturais e à valorização de sua pátria. Um inventor de máquinas e implementos agrícolas, um analista de métodos de cultivo, um pesquisador pioneiro da flora, fauna e recursos naturais de toda uma imensa região que vai do rio São Francisco aos sertões do Piauí. $^{11}$

Observa-se, com base neste trecho, que os pesquisadores oriundos do Mundo de Queluz, sendo Arruda da Câmara um deles, influenciados pela visão cientificista e empirista das Luzes, não se limitavam apenas em descobrir e catalogar espécimes dos "três reinos da natureza" - mineral, animal e vegetal - mas também, conforme ressalta Munteal Filho (1999), buscavam o aperfeiçoamento técnico da agricultura das colônias, valorizando a "industriosidade" e o empenho dos que se dedicassem à pesquisa dos novos métodos que deveriam ser utilizados no desenvolvimento do cultivo da terra. Em relação a Arruda da Câmara, tais esforços podem ser observados através do desenvolvimento de técnicas agrícolas capazes de aperfeiçoar o desenvolvimento da cultura do algodão, entre elas, 
a invenção de um descaroçador para melhorar a dinâmica agrícola da região.

Embora os marcos cronológicos e espaciais deste trabalho sejam os itinerários de Arruda da Câmara pelos Sertões das Capitanias da região Nordeste do Brasil, sabe-se que as expedições científicas realizadas por esse naturalista não se limitaram apenas a esses territórios, pois ele também atuou em outras paragens antes e depois do retorno a Pernambuco.

Dr. Manoel de Arruda Câmara - formado em Medicina pela Universidade de Montpellier - depois de acompanhar a José Bonifácio em parte das suas incursões científicas pela Europa, regressou a Pernambuco, onde já se achava em 1796 entregue ao exercício da Medicina, quando foi incumbido pelo governo do exame e indagações das suas nitreiras naturais, bem como, posteriormente, de outras missões científicas em várias partes do país e de objetos diversos, e por fim demorando-se algum tempo no Rio de Janeiro, foi eleito membro da nova academia científica, criada no tempo do vice-rei Luís Barão de Goiana de Vasconcelos e Souza, e fêz parte da comissão incumbida de dar parecer e aperfeiçoar a Flora Fluminense de Frei José Mariano da Conceição Veloso. ${ }^{12}$

Através deste registro documental, observamos que o naturalista manteve ligações profissionais com o grupo de José Bonifácio de Andrade e Silva, reformista ilustrado que exerceu um eminente papel político e econômico no Império brasileiro, cujas idéias marcaram a história e o pensamento intelectual do país, sendo ainda considerado um dos mais importantes e influentes defensores dos bens naturais, numa perspectiva econômica, do Brasil colonial e imperial. Manuel Arruda da Câmara foi um desses intelectuais que também conseguiu se projetar nacionalmente, sendo considerado um dos mais importantes botânicos/naturalistas dos fins do Setecentos.

Com relação à sua atuação nos Sertões das Capitanias do Nordeste do Brasil, objeto da presente análise, é notório que os relatórios, as memórias e demais escritos por ele produzidos a respeito dos "produtos naturais e das úteis manufaturas" das 
colônias eram resultados dos trabalhos encomendados pelos governadores e ministros nomeados pela Coroa e os resultados das pesquisas eram remetidos à Europa logo que conseguisse descobrir, realizar experiências e coletar os espécimes de utilidade prática para os intelectuais e burocratas da Metrópole.

Conforme podemos perceber em Memória sobre a cultura dos algodoeiros, escrita em 1797, Arruda da Câmara ofereceu ao príncipe regente através desta remessa as "primeiras observações agronômicas" que tinha feito no Brasil, "ardendo no desejo de ser útil" à sua "Nação pelos conhecimentos que tinha adquirido em as ciências naturais". As palavras dirigidas a Dom Rodrigo de Souza Coutinho ao concluir a escrita das suas Memórias ilustram bem a visão desse naturalista em relação às culturas agrícolas do Sertão:

Os primeiros frutos dos meus trabalhos estudiosos e as primícias das experiências que tenho incansavelmente feito sobre uma plantação que faz hoje na Europa mercantil um dos mais ricos ramos do comércio da América, não deviam ser consagrados senão a um Ministro que, do pé mesmo do Trono, estende suas penetrantes vistas até os nossos férteis campos e deles procura extrair suas preciosas produções... ${ }^{13}$

Esse oferecimento direcionado ao Ministro de Ultramar delineia de forma explícita os objetivos do naturalista em remeter os primeiros resultados dos seus trabalhos à Coroa, com o intuito de favorecer o beneficiamento dos recursos naturais dos Sertões da Colônia. Conforme salienta Munteal Filho, as ordens régias quanto ao mapeamento das potencialidades econômicas das colônias eram claras com o objetivo de reverter o precário controle pela burocracia lusa sobre esses domínios. As atividades dos naturalistas giravam em torno das orientações da Coroa portuguesa, que partiam especialmente da secretaria dos domínios ultramarinos.

Para tanto, Arruda da Câmara afirma não ter economizado esforços no sentido de melhorar tanto a cultura quanto o beneficiamento do algodão no comércio português: 
O acaso, porém, me tem posto nas circunstâncias de fazer experiências, observações e algumas descobertas úteis em outra cultura [a do algodão], não menos interessante ao comércio, tanto de Portugal quanto de Paranambuc... ${ }^{14}$

O "fiel vassalo" de Sua Majestade também relata as diligências feitas e das dificuldades enfrentadas na Capitania de Pernambuco e em suas anexas com o intuito de servir ao Reino:

Embaraçaram porém o meu projeto as grandes secas que nessa época assolaram toda esta Capitania, e me determinaram a reparar toda a perda que tinha experimentado, por uma grande plantação de Algodão nas margens do Rio Paraíba do Norte, a que assisti constante. ${ }^{15}$

Observamos neste trecho, além do registro da visão e sensibilidade do naturalista em relação às especificidades climáticas das Capitanias, a sua busca em experimentar as espécies botânicas da Colônia e as vantagens que elas poderiam trazer para a Metrópole. Assim como os demais membros do subgrupo da Academia Real de Ciências de Lisboa, a concepção empírica e cientificista de Arruda da Câmara é a prioridade ao observar os recursos naturais brasileiros. Para ele, os naturalistas devem viver nos campos para observarem de perto a natureza e proferirem instruções para os seus semelhantes e não se confinar em seus gabinetes.

Os trabalhos empíricos de Arruda da Câmara visavam o progresso econômico e político da Metrópole e da Colônia, conforme podemos observar:

Na Paraíba foi onde primeiro sonharam em mandar algodão para Portugal; mas o estímulo da ambição não picava muito os ânimos amortecidos e encolhidos debaixo da pobreza a cultivarem-no com a energia de que eram capazes. A notícia do grande lucro que podia dar o algodão, a quem o cultivasse, foi penetrando pouco a pouco os matos e despertando os agricultores. Nos anos de 1877 até 1781 animaram-se os povos de uma nova força, então é que se viram os interiores dos Sertões mais habitados e 
cultivados, e tem-se de tal modo fomentado a cultura e o negócio do algodão, que admira. ${ }^{16}$

Constata-se através deste trecho a forma como a exploração econômica do algodão contribuiu para o desbravamento das matas dos Sertões das Capitanias do Norte e como os agricultores adentraram os interiores sertanejos com o intuito de obter lucros através do cultivo do algodão, muito valorizado no comércio internacional nesse momento histórico.

Ainda podemos observar os resultados econômicos da cultura algodoeira para despertar o interesse dos "rústicos", através do trecho que se segue:

Daqui se vê quanto é importante a cultura do algodão em Paranambuc, pois o grande lucro que promete, impele a todos ao trabalho, tirando-os da ociosidade, dá valor às terras que dantes o não tinham, com sumo proveito do proprietário; anima o negociante ao mais vivo tráfico fazendo o mais importante o nosso porto e mais freqüentado o de Lisboa pelos estrangeiros, que dão todo o consumo... ${ }^{17}$

O trecho supracitado nos leva a refletir sobre a ousada concepção nacionalista de Manuel Arruda da Câmara, proposta por Warren Dean, em detrimento da metrópole abandonada. Os documentos arrolados nos levam a compreender que não obstante o cientista exaltar o potencial natural das terras brasileiras, ele também tenta taticamente conciliar esse potencial com o progresso econômico da Metrópole. Em outras palavras, a ambiguidade do trabalho de Arruda da Câmara reside em tentar conciliar o pensamento utilitário e $\mathrm{o}$ naturalismo empírico dos sócios da Academia Real de Ciências de Lisboa, concepção da qual ele fazia parte, com a valorização e a desconstrução dos estereótipos construídos pelos europeus a respeito da natureza do Brasil colônia. São esses aspectos que flagramos no registro documental acima destacado, quando o naturalista tenta dividir pacificamente o progresso econômico entre a Colônia e a Metrópole. 
Para Arruda da Câmara, "a natureza concedeu a cada país ou a cada clima seus privilégios exclusivos, e que sempre usufruíram, apesar do esforço da Arte"18. O lugar próprio à cultura do algodoeiro seria debaixo dos Trópicos, na América ou na Índia, onde essa planta crescia naturalmente. Nesse sentido, observamos o momento em que o naturalista, além de buscar os interesses comerciais e políticos da Corte portuguesa para a qual trabalhava, exalta a sua terra natal, mostrando que os países coloniais eram muito mais férteis que a Europa, misturando o nacionalismo e a botânica para reverter os preconceitos acalentados pelos portugueses em relação às terras coloniais ${ }^{19}$.

Outro aspecto que também é possível analisar na obra de Arruda da Câmara é a visão do cientista em relação à utilização da mão-de-obra dos escravos negros para desenvolver a cultura do algodão. Para ele, seria um grande erro para o proprietário de terras cultiváveis

Mandar os escravos colher algodão à ventura, isto é, por onde lhes parecer; estes assim que se ocultam nos arbustos, ou dormem e nutrem a sua natural preguiça, ou se colhem, roubam de cada vez uma porção e escondem nos matos, te acharem ocasião de o desencaminhar, e fazem o seu contrabando com tanta sagacidade que rara vez se sabe... ${ }^{20}$

Para Arruda da Câmara, os escravos negros "usam de mil modos para enganar", por isso, seria necessário que o trabalho deles fosse realizado sob disciplina e vigilância, conforme observamos também abaixo:

O feitor seguindo os cativos, cada um deles armado de um cesto, irá ao lugar determinado, onde deve principiar o serviço daquele dia: aí cada escravo toma a sua conta uma fileira de algodoeiros, que a não deve deixar até o fim, colhendo não só o que se achar por cima, senão ainda pelo chão, no que deve o feitor pôr um extremo cuidado, para cujo efeito os deve ter sempre debaixo da vista, e passear naquela esteira, para o que contribui muito a 
ordem em que se devem plantar os algodoeiros; ele deve castigar ou repreender qualquer negligência da parte dos escravos... ${ }^{21}$

Tais atitudes demonstram que o naturalista, embora suponhamos que tenha tido influencia das Luzes na defesa dos ideais de igualdade, fraternidade e solidariedade, esses ideais democráticos não o influenciaram em relação aos escravos negros das colônias, uma vez que o próprio naturalista era um proprietário de escravos e indicava métodos de disciplina para melhor aproveitamento da mão-de-obra escrava. Sabe-se que a questão da Abolição do trabalho servil foi motivo de muitas controvérsias durante o Império brasileiro. Por um lado, havia alguns reformistas ilustrados que, inspirados no pensamento de José Bonifácio, defenderam reformas sociais mais profundas, propondo o fim do trabalho escravo, por outro, no entanto, havia aqueles intelectuais que defendiam que a escravidão negra fosse mantida. Conforme observamos, Manuel Arruda da Câmara, embora tenha convivido em algum momento com José Bonifácio, não foi influenciado por ele no sentido de libertar os cativos negros e negras, uma vez que defendia a utilização da mão-de-obra desses escravos para o progresso econômico da Colônia.

As questões de gênero também estão relacionadas com este aspecto na obra de Manuel Arruda da Câmara, conforme o exposto:

Quem mete nos buracos a semente comumente são negras, por isso é que mando sempre aos que andam com as enxadas, mudar as estacas; porque estes são negros, por isso, mais ligeiros que aquelas, qualidade que se requer para este serviço não padecer demasiada demora. ${ }^{22}$

Constatamos aqui que o naturalista menospreza a atuação das mulheres escravas negras no desenvolvimento da agricultura colonial, embora possamos perceber no registro documental que elas foram atrizes e participaram ativamente 
desse processo. A incorporação dos estudos de gênero à história tem questionado a vitimização e as invisibilidades a que as mulheres têm sido submetidas pela historiografia em relação à sua participação como atrizes sociais co-participantes do trabalho, da busca pela sobrevivência e pela preservação dos recursos da natureza. Essas relações de gênero na história requerem uma crítica mais profunda quando se trata da atuação das escravas negras no Nordeste colonial, uma vez que, pela passagem supracitada, percebemos que as condições desumanas e de desvalorização a que os escravos eram submetidos nesse período tornavam-se mais intensas quando se tratavam de mulheres. ${ }^{23}$

Em 1810, Manuel Arruda da Câmara lançou o Discurso sobre a utilidade da instituição dos jardins nas principais províncias do Brasil, através do qual, como o próprio título da publicação sugere, defendia a importância de que "entre os estabelecimentos úteis a este novo Império" fossem instituídos Hortos Públicos nas principais Capitanias do Brasil, com a finalidade de transplantar não apenas plantas de países estranhos, mas também de várias outras partes do Brasil, utilizando como critério a raridade das espécies a ser aclimatadas cuja destruição seria inevitável, por causa da extensão do país e da pouca população.

Em tom de exaltação à natureza brasileira, Arruda da Câmara relata:

Se lançarmos um golpe de vista filosófico sobre a superfície do globo, veremos que os países situados entre os Trópicos parecem ser os únicos destinados pela natureza para habitação dos homens; pois que só ali é que ele pode viver comodamente sem o socorro d'Arte, e nutrir-se dos inumeráveis frutos que a terra prodigamente lhe liberaliza, e que se não encontram nos países vizinhos aos pólos. ${ }^{24}$

Embora a ambiguidade do pensamento de Arruda da Câmara seja flagrante nesse trecho, em que ele tenta conciliar o beneficiamento dos produtos agrícolas para a exportação e para 
o alimento da população colonial, observamos que o nacionalismo do naturalista transparece em relação ao potencial botânico do Brasil colonial, deixando implícita uma crítica à Metrópole em período de crise.

Desde o Rio da Prata até o Orenoque, de que hoje nos achamos de posse, não se encontrará com facilidade um palmo de terra que não possa convir à cultura de algum vegetal, ou este sirva ao consumo dos habitantes, ou à exportação. ${ }^{25}$

Sem qualquer pretensão ou busca de conservação do ambiente natural da Colônia, conforme sugeriu Pádua (1999), as tentativas de instituição dos Jardins Botânicos nas diversas províncias do Brasil tinham preocupações eminentemente utilitárias, econômicas, políticas, cientificistas e progressistas, aspectos que compuseram o mosaico do pensamento intelectual dos reformistas ilustrados.

É, pois, manifesto que sendo o continente do Brasil desde o Rio da Prata até o Orenoque tão extenso e tão variado em climas e terras, é susceptível, não só de nele cultivarem as plantas da Europa, África e Ásia; mas de aí se naturalizarem as de uma em outras províncias; e cumpre muito à Nação que se isto faça com a maior presteza e energia, tanto para cômodo e abastança de todo o Estado, como para aumento do comércio e maior freqüência de seus portos; o que também não pode deixar de favorecer a população, de que tanto e tanto necessita. ${ }^{26}$

A ambiguidade do pensamento de Arruda da Câmara é observada também em relação às tentativas de aclimatação das plantas nacionais ou estrangeiras nas províncias, uma vez que os resultados desse processo são compreendidos como sendo favoráveis à população colonial e à economia metropolitana. Vale ressaltar, no entanto, com base em Dean (1996), que ele exaltava a fertilidade das colônias tropicais de detrimento do clima da Metrópole, desfavorável a diversificação agrícola.

$\mathrm{O}$ objetivo de atender às demandas econômicas da Coroa portuguesa é, porém, logo evidenciado: 
Como a instituição de semelhantes Hortos não tem por objeto só o agradável e o aumento da Botânica, mas o seu principal fim é o útil, para que a sua manutenção não seja tão onerosa ao Estado, devem os Inspetores promover o mais que puderem, a cultura daquelas plantas que derem mais lucro. ${ }^{27}$

É compreensível que o naturalista, mesmo com suas concepções nacionalistas, buscasse atender às solicitações régias e se preocupasse em remeter espécimes de potencial econômico para Portugal, visto que ele estava sendo financiado e encarregado para tal atividade nos sertões coloniais. Warren Dean cita Manuel Arruda da Câmara e a crítica que ele faz ao Estado português por não ter instituído jardins botânicos em suas colônias a fim de que pudesse conhecer e a explorar as riquezas naturais desses territórios, encetando assim uma pertinente critica à política colonial e às práticas botânicas anteriores.

Por fim, destacamos o fragmento documental que enfatiza o ponto de vista nacionalista de Arruda da Câmara:

Cuido que desta maneira se verá em pouco tempo o Brasil mais enriquecido e independente das outras partes do mundo, no que respeita às produções que a Natureza espalhou por todas: ajuntemo-las e apropriemo-las; e se a isto se ajuntar, ainda, a indústria de manufaturas, ao menos as bastantes para o nosso consumo (o que é muito de esperar do nosso sábio Ministério) que império haverá no mundo igual a este ${ }^{28}$

Com base nas considerações apresentadas anteriormente e no fragmento documental supracitado, observamos que o cientista efetivamente direcionou o pensamento naturalistautilitário da Academia Real de Ciências de Lisboa e outros conhecimentos adquiridos durante seus estudos na França para defender a natureza, a independência e a população livre do Nordeste colonial, não obstante também buscasse o enriquecimento e a superação da crise da Coroa portuguesa.

Sobre a ação política do naturalista, algumas autoridades judiciais pernambucanas apontavam-no como o primeiro a difundir idéias liberais e republicanas no Nordeste. Tal atribuição se deve ao fato de que ele esteve na França, em 1890, 
quando deixou a Universidade de Coimbra e foi para Montepellier, convivendo com toda a atmosfera político-cultural pós-Revolução. Esse presumido ideário democrático tem levado inclusive a estimativas de sua participação na Revolução Pernambucana de 1817, além de possível elaboração, juntamente com dois amigos, de ter elaborado um documento, em 1799, declarando a constituição de uma República Federativa a ser implantada no Nordeste. Essas conjecturas baseadas em estudos biográficos realizados por Gonsalves (1982) apontam para a necessidade de realização de outros trabalhos que abordem especificamente 0 aspecto político da vida do naturalista. Além disso, o paradoxo a respeito da gente de cor, certo indigenismo presente em sua obra, o orgulho de pertencer à Terra Brasilis, o patriotismo do naturalista, etc. destacam como indagações passíveis de maior aprofundamento documental e teórico. Por fugir aos propósitos desta pesquisa, limita-nos a analisar a visão que o naturalista elaborou em relação às interrelações históricas entre sociedades e naturezas durante a transição colônia-império.

\section{Nacionalismo e Reformismo Ilustrado em Manuel Arruda da Câmara}

Para todos os viajantes europeus, e, conforme veremos, também para o naturalista viajante Manuel Arruda da Câmara, a Europa era o centro de tudo o que se produzira de melhor e mais refinado na cultura humana. Dar oportunidade aos povos conquistados de usufruir destas conquistas e conduzi-los paternalisticamente a um estado superior de "civilização" passava então a ser uma obrigação histórica e filantrópica dos homens ilustrados. Este discurso justificou diversas intervenções no âmbito das nações indígenas. Mary Louise Pratt chamou de anticonquista às estratégias de representação através das quais "os agentes burgueses europeus procuram 
assegurar sua inocência ao mesmo tempo em que asseguram a hegemonia européia". ${ }^{29}$

Os viajantes representavam-se na condição de observadores esclarecidos, capazes de não apenas descrever e denunciar "injustiças", mas também de propor soluções e intervenções sobre a ação dos governos e autoridades que administravam os territórios visitados. A superioridade européia era assim confirmada para os leitores europeus de seus livros. A validação desta "preeminência caucásica" contava inclusive com o respaldo dos "saberes científicos" de que os naturalistas eram protagonistas.

Por outro lado, o discurso de viajantes como Koster, Spix, Martius e Saint-Hilaire foi também, e frequentemente, um discurso de "anticonquista", na medida em que sua validação foi sempre permeada por constantes estratégias de afirmação de inocência. Dentre elas, talvez, a mais recorrente tenha sido a justificação pedagógica da violência, que me parece perfeitamente coerente com o espírito de seu tempo. Não devemos perder de vista a constatação de que, nos séculos XVIII e XIX, violência física e pedagogia andavam quase sempre juntas ${ }^{30}$.

O reformismo ilustrado presente na Academia Real de Ciências de Lisboa, que influenciou profundamente a "geração ilustrada" de intelectuais luso-brasileiros, entre eles, Manuel Arruda da Câmara, em fins do século XVIII e inícios do XIX, visava exclusivamente redirecionar a política colonial da Metrópole. Nesse momento histórico, Portugal se encontrava em crise diante da concorrência com outras potências européias e perdia parte de seus territórios ultramarinos. Conforme observamos, esse grupo de intelectuais naturalista-utilitários constituíram um sub-grupo no interior da Academia com o intuito de redirecionar a política colonial da Coroa e de recuperar o Reino da crise. Longe de se constituírem como defensores do ambiente natural colonial pelo valor intrínseco que deveria ser atribuído à natureza, enquanto parte do patrimônio histórico e ambiental da Coroa, os esforços de conservação empreendidos durante $\mathrm{o}$ reformismo ilustrado estavam diretamente 
relacionados com o progresso econômico e político da Coroa portuguesa. Nesse sentido, não devemos confundir a tradição intelectual ilustrada e os seus esforços de conservação com o ambientalismo moderno, uma vez que são contextos diferentes e a consciência da necessidade de preservação do ambiente natural como forma de assegurar a vida no Planeta, emergiu muito tempo depois.

A peculiaridade da observação esclarecida de Manuel Arruda Câmara é flagrante, uma vez que ele era um reformista ilustrado, interlocutor das concepções cientificistas e progressistas européias, mas não constituiu um olhar de estranhamento em relação à natureza tropical, uma vez que esta lhe era familiar por ele ser natural dessas plagas.

Como membro dessa geração ilustrada, Manuel Arruda da Câmara também assimilou esse ideário progressista e de beneficiamento econômico da Metrópole, buscando coletar espécimes capazes de encaminhar e de desenvolver a economia do Reino de Portugal. Para isso, desenvolveu técnicas agrícolas, realizou expedições científicas, remeteu relatórios, trabalhos e memórias para Sua Majestade, que tinha encomendado descobertas botânicas nos Sertões das Capitanias do Nordeste. Não obstante ele ter defendido a concepção naturalista-utilitária dos demais reformistas ilustrados, não hesitou em utilizar seus conhecimentos em Ciências Naturais para desenvolver a Colônia brasileira. Mesmo cumprindo as ordens régias para as quais havia sido incumbido, não renunciou em favorecer as Capitanias do Nordeste e de todo o país com os resultados de suas pesquisas e experimentações. Nesse sentido, concordamos com Dean (1996) quando ele relata a ousadia de Arruda da Câmara em defender a natureza brasileira e sua sociedade, em alguns casos, até mesmo taticamente, fez isso em detrimento dos interesses Coroa.

Percebe-se, através deste trabalho, resultado de incursões feitas a partir de uma proposta inicial de pesquisa, que muitas indagações, questionamentos e curiosidades foram suscitadas e esclarecidas a respeito da forma como os naturalistas e viajantes europeus perceberam e representaram a paisagem colonial 
brasileira e nordestina e a forma como as sociedades se interrelacionaram com o meio ambiente durante $o$ início do Oitocentos. Em relação à Arruda da Câmara, muitos aspectos da paisagem natural e cultural nordestina durante a transição Colônia-Império foram delineados de forma menos estereotipada, menos exótica e mais humanizada; esperamos que outras pesquisas venham a aprofundar tais perspectivas e suscitar novas questões. A obra de Arruda da Câmara situa-se como uma exceção diante das visões europocêntricas e estereotipadas que se elaborou no período colonial brasileiro em relação ao nosso povo e à nossa natureza, que já não era vista por esse naturalista apenas como sinônimo do exótico, mas possuindo potencialidades que, apesar do enfoque economicista típico à historicidade da época, pode se colocar hoje como uma tentativa de entender as práticas cotidianas construtivas que se realizam no ambiente natural do Nordeste, crítica fundamental apontada por Schama aos historiadores catastrofistas.

\section{REFERÊNCIAS BIBLIOGRÁFICAS}

Obras de Manuel Arruda da CÂMARA:

1) A memória sobre a cultura do algodoeiro, 1797;

2) Dissertação sobre as plantas do Brasil, 1817;

3) Discurso sobre a vitalidade da instituição de jardins nas principais províncias do país, 1810;

4) Aviso aos lavradores sobre a suposta fermentação de qualquer qualidade de grãos ou pevides para aumento da colheita, Lisboa, 1792;

5) Memórias sobre as plantas de que se podem fazer baunilha no Brasil;

6) Memórias sobre o algodão de Pernambuco, Lisboa, 1810;

7) Tratado de Agricultura;

8) Tratado da lógica;

9) Textos manuscritos de Manuel Arruda da Câmara; 
10) Textos atribuídos a Manuel Arruda da Câmara;

11) Documentos respeitantes a Manuel Arruda da Câmara e sua obra;

12) Apensos relativos a Manuel Arruda da Câmara;

13) Desenhos de vegetais da obra de Manuel Arruda da Câmara;

14) Anais pernambucanos - Vol. VII - Manuel Arruda da Câmara. CD-rom

15) Estudo biográfico escrito por José Antônio Gonsalves de Mello.

ANJOS JÚNIOR, João Alfredo dos (Org.) Viajantes ingleses no Nordeste do Brasil no século XIX. Recife: Fundaj; Instituto de Documentação. Biblioteca Central Blanche Knopf; The British Council, 1991. [Não paginado]. Catálogo de exposição bibliográfica.

BELLUZZO, Ana Maria de M. O Brasil dos Viajantes. 2 ed. 3 vol. São Paulo: Metalivros; Rio de Janeiro: Objetiva, 1999.

BELLUZZO, Ana Maria. A propósito do Brasil dos viajantes. Revista da USP (Dossiê Brasil dos Viajantes), São Paulo, n. 30, p. 9-20, 1996

BRANDÃO, Carlos Rodrigues. Do sertão à cidade: quantos territórios!. In Territórios do cotidiano: uma introdução a novos olhares e experiências. Porto Alegre: Editora da Universidade/UFRGS, EDUNISC, 1995.

${ }^{1}$ CÂMARA, Manuel Arruda da. Obras reunidas. Com estudo biográfico de José Antônio Gonsalves de Mello. Recife, PE: Fundação de cultura cidade de Recife, 1982. p. 111

CASTORIADIS, Cornelius. As encruzilhadas do labirinto: os domínios do homem. Tradução José Oscar de Almeida Marques. Rio de Janeiro: Paz e terra, 1987.

CASTRO, Eduardo Viveiros de. imagens da natureza e da sociedade. In: A inconstância da Alma selvagem: e outros ensaios de antropologia. São Paulo: Cosac \& Naify, 2002, p. 338.

DEAN, Warren. A ferro e fogo: a história e a devastação da Mata Atlântica brasileira. Tradução Cid Knipel Moreira. São Paulo: Companhia das Letras, 1996.

D'ORBIGNY, Alcide. Viagem pitoresca através do Brasil. Belo Horizonte: Itatiaia, São Paulo: Edusp, 1976.

DANTAS, George A. F.; FERREIRA, Angela L. A. e FARIAS, Hélio T. M. A dimensão técnica das secas (formulações iniciais, leituras do território e planejamento na virada para o século XX), 2006 [artigo inédito]. 
DRUMMOND, José Augusto. A História Ambiental: temas, fontes e linhas de pesquisa. In: Estudos Históricos. Rio de Janeiro, 4(8), 1991, p.177-197.

FERRAZ, Joaquim de Sampaio. A meteorologia no Brasil. In: Fernando de Azevedo (org). As ciências no Brasil. São Paulo: Melhoramentos, 1980. p. 205-240.

FERREIRA, A.L. DANTAS, G.A.F. FARIAS, H.T.M. Adentrando sertões: considerações sobre a delimitação do território das secas. Scripta Nova. Revista electrónica de geografía y ciencias sociales. Barcelona: Universidad de Barcelona, 1 de agosto de 2006, vol. X, núm. 218 (62). <http://www.ub.es/geocrit/sn/sn-218-62.htm> [ISSN: 1138-9788] FOUCAULT, Michel. Microfísica do Poder. 9 ed. Rio de Janeiro: Graal, 1990. [orig. 1979]

JAMES, Preston E. Observations on physical geography of Northeast Brazil. Annals of Association of American Geographers, v.42, n.02, pp.153-176, jun. 1952.

MARTINS, Luciana M. O Rio de Janeiro dos viajantes: o olhar britânico (1800-1850). Rio de Janeiro: Jorge Zahar, 2001.

MONTEL FILHO, Oswaldo. Política e natureza no reformismo ilustrado de Dom Rodrigo de Souza Coutinho. In: PRADO, Maria Emília. O Estado como vocação: idéias e práticas políticas no Brasil oitocentista. Rio de Janeiro: Access, 1999. p. 81-110

MORAES, Antonio Carlos Robert. "O Sertão: Um 'Outro' Geográfico. Terra Brasilis, Rio de Janeiro/RJ, ano III-IV, n. 4-5, p.11-23, 2003.

PÁDUA, José Augusto. Um sopro de destruição: pensamento ambiental e crítica escravista no Brasil (1779-1888). São Paulo: Cia das Letras, 2003.

PERRONE-MOISES, Leyla. Alegres trópicos: Gonneville, Thevet e Léry. Revista da USP (Dossiê Brasil dos Viajantes), São Paulo, n. 30, p. 85-94, 1996.

PRATT, Mary Louise. Os olhos do império: relatos de viagem e transculturação. Bauru (SP): Edusc, 1999.

RAMINELLI, Ronald. Do conhecimento físico e moral dos povos: iconografia e taxonomia na Viagem Filosófica de Alexandre Rodrigues Ferreira. História, Ciências, Saúde Rio de Janeiro: n.8, p. 969-992, 2001, p. 972. suplemento.

REBORATTI, Carlos E. Fronteras agrarias en Latino América. Geo Critica: Cuadernos Críticos de Geografia Humana, Barcelona: Universidad de Barcelona, n.87, mayo 1990 [reproducido em Scripta Vetera, edición electrónica de trabajos publicados sobre Geografia y 
Ciências Sociales, sv-26, <www.ub.es/geocrit/sv-26.htm>. [12 de fevereiro de 2006]. ISSN: 1578-0015.

STADEN, Hans. Duas viagens ao Brasil. Belo Horizonte, MG: Itatiaia e São Paulo: Edusp, 1974. 216 p. (coleção Reconquista do Brasil, v. 17). Publicado originalmente em 1557

AGUIAR, José Otávio; BURITI, Catarina de Oliveira. Environment and Culture in the Captaincies of the Brazilian Colonial Northeast: Nationalism and Reforms Illustrated in the Work of the Nature Explorer, Manuel Arruda Da Câmara (1793-1814). História, v.28, n.1, p.347-380, 2009.

\begin{abstract}
This study proposes to raise a discussion about the images and visions of nature explorers who were traveling in the Northeast of Brazil at the end of the eighteen century and the beginning of the nineteenth with respect to the natural environment of this territory. The objective is to investigate the interaction between nature and culture in the work of nature explorer, Manuel Arruda da Câmara, in the Northeast Captaincy during the Colony-Empire transition. Observations can be made that although this scientist was working in the colonial Northeast Captaincy and aiming to satisfy the economic and political interests of the Kingdom of Portugal, he glorified the natural surroundings of the tropical colonies, and also sought to encourage the population of Brazil to follow suit. Therefore, even though playing a part of the Luso-Brazilian "illustrated generation", this nature explorer's nationalism led him to highly value the colonial natural environment.
\end{abstract}

Keywords: Environment; History; Explorers; Colonial Brazil.

\title{
NOTAS
}

${ }^{1}$ Expressão utilizada por Simon Schama quando se refere à importância de que os historiadores do ambiente valorizem a observação da natureza. Neste trabalho, o acesso às paisagens do Nordeste de fins do 
século XVIII e início do XIX torna-se possível através da obra do naturalista Manuel Arruda da Câmara, objeto da presente análise. Ver SCHAMA, Simon. Paisagem e memória. Tradução Hildegard Feist. São Paulo: Cia. das letras, 1996.

${ }^{2}$ Esse é um termo genérico utilizado para o que é hoje geralmente visto como um conjunto variado de disciplinas científicas distintas. A maior parte das definições incluem o estudo das coisas vivas (ex: biologia, incluindo botânica e zoologia), enquanto que outras definições estendem o conceito até incluir a paleontologia, a ecologia ou a bioquímica, bem como partes da geologia e da fisica e até mesmo da meteorologia. Nos séculos XVIII e XIX, os profissionais especializados em História Natural, os naturalistas, utilizavam o termo para se referir aos estudos científicos e se contrapor à história eclesiática e apaixonada, sem fundamentação empírica.

3 Para maiores informações acerca da relação entre paisagem e memória, ver a obra do historiador britânico SCHAMA, Simon. Paisagem e memória. Tradução Hildegard Feist. São Paulo: Cia. das letras, 1996.

${ }^{4}$ A Paraíba homenageou Manuel Arruda da Câmara, dando seu nome a um Parque Zôobotanico, misto de reserva florestal e de zoológico existente no centro da capital. Mais conhecida como "Bica", a reserva compreende uma área de 43 hectares que foi desapropriada pelo então prefeito Walfredo Guedes Pereira (1920-1924) e batizada com o nome do botânico da cidade de Pombal.

${ }^{5}$ Veja, sobre este assunto, a excelente introdução para a edição brasileira de A Revolução da América. FIGUEIREDO, Luciano Raposo Almeida; MUNTREAL FILHO, Osvaldo. Introdução. In: RAYNAL, Guilherme Thomas. A revolução da América. Rio de Janeiro: Arquivo Nacional, 1993. p.

${ }^{6}$ Sobre o jusnaturalismo veja verbete correspondente em: FASSO, Guido. Jusnaturalismo. In:.BOBBIO, Norberto; MANTTEUCCI, Nicola; PASQUINO, Gianfranco. Dicionário de Política. Brasília: UNB, 1994. Ver também: CASTRO, Zília Ozório de. Cultura e política: Manoel Borges Carneiro e o Vintismo. Lisboa: Instituto Nacional de Investigação Científica, 1990. V.2, cap.1, p.565-585.

${ }^{7}$ Sobre o empirismo e o pragmatismo do reformismo ilustrado no Brasil ver: DIAS, Maria Odila da Silva. Aspectos da ilustração no Brasil. Revista do Instituto Histórico e Geográfico do Brasil. Rio de Janeiro, n. 278, p. 105- 169, mar. 1968. 
8 SANTOS, Estilaque Ferreira dos. A Monarquia no Brasil: o pensamento político da independência. Vitória: Edufes, 1999. p. 32. Veja aqui, como exemplo, o caso do professor de Geometria José Anastácio da Cunha, interrogado em Portugal pelo tribunal da Inquisição logo após a queda de Pombal, sob a acusação de ateísmo.

${ }^{9}$ Cf. sobre as idéias de Dom Rodrigo de Souza Coutinho: discurso pronunciado pelo Ministro Rodrigo de Souza Coutinho perante a Junta de Ministros e outras pessoas sobre assuntos referentes ao desenvolvimento econômico e financeiro de Portugal e domínios ultramarinos. 1803, Biblioteca Nacional do Rio de Janeiro. Setor de Manuscritos. Coleção Linhares.

${ }^{10}$ Veja: Memória escrita por Dom Rodrigo de Souza Coutinho sobre a mudança da sede da Monarquia Portuguesa, 1803. Biblioteca Nacional do Rio de Janeiro. Setor de Manuscritos. Coleção Linhares.

${ }^{11}$ Cf. GONÇALVES, 1982, p. 9.

${ }^{12}$ Cf. Anais Pernambucanos. vol. 5. p. 97-8.

${ }^{13}$ CÂMARA, 1982. p. 111

${ }^{14}$ Cf. Ibidem, p. 113

${ }^{15}$ Cf. Ibidem, p. 111

${ }^{16}$ Cf. Ibidem, p. 117

${ }^{17}$ Cf. Ibidem, p. 118

${ }^{18}$ Cf. Ibidem, p. 123

${ }^{19}$ Cf. DEAN, 1996, p. 142

${ }^{20}$ Cf. Ibidem, p. 148

${ }^{21}$ Cf. Ibidem, p. 147

${ }^{22}$ Cf. Ibidem, p. 131

${ }^{23}$ Para maiores informações sobre a incorporação da perspectiva de gênero à pesquisa histórica, ver MACHADO, Lia Zanotta. Gênero, um novo paradigma? In: Cadernos Pagu. n.11, 1998. p. 107-125. Em relação a atuação das mulheres na história e a contestação de suas invisibilidades ver MONTYSUMA, Marcos. Gênero e meio ambiente: uma (in)visibilidade das mulheres na construção das florestas na Amazônia. In: PARENTE, Temis Gomes; MAGALHÃES, Hilda Gomes Dutra. Linguagens plurais: cultura e meio ambiente. Bauru, SP: EDUSC, 2008. p. 155-174

${ }^{24}$ Cf. CÂMARA, 1982, p. 198

${ }^{25}$ Cf. CÂMARA, 1982, p. 201

${ }^{26}$ Cf. Ibidem, p. 202

${ }^{27}$ Cf. Ibidem, p. 204

${ }^{28}$ Cf. Ibidem, p. 204 
${ }^{29}$ Cf. PRATT, 1999, p.32.

${ }^{30}$ Sobre essa violência pedagógica que, ao meu ver, parece associar-se ao conceito foucaultiano de poder disciplinar veja: FOUCAULT, Michel. Vigiar e punir: história da violência nas prisões. Petrópolis: Vozes, 1987.

Artigo recebido em 02/2009. Aprovado em 05/2009 